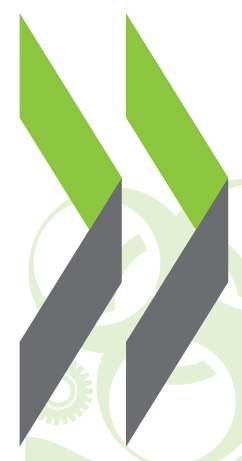

\title{
Do gender gaps in reading and mathematics evolve between childhood and adulthood?
}

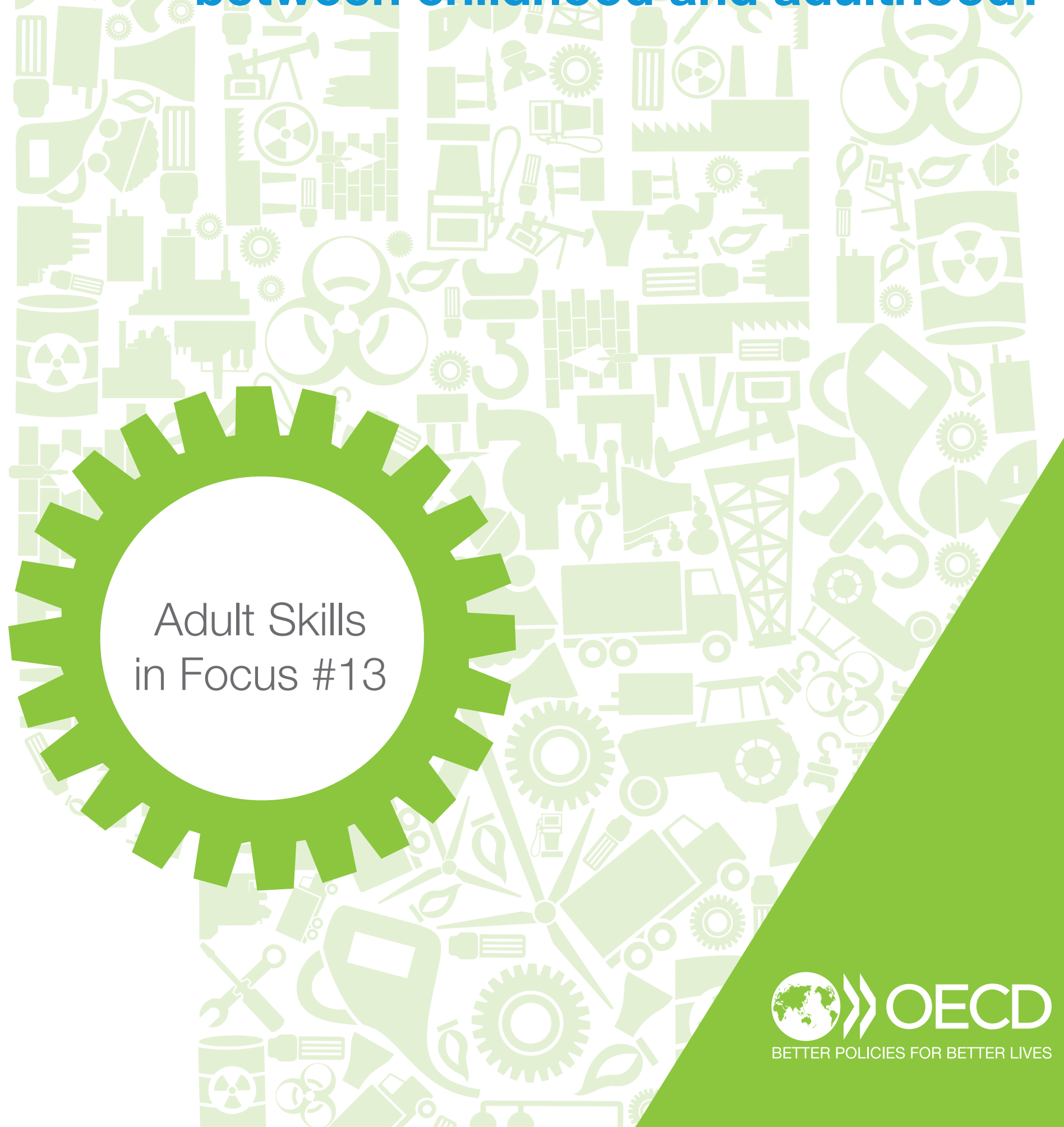




\section{ADULT SKILLS}

INFOCUS

- Girls' advantage over boys in reading performance peaks during adolescence, but then disappears by early adulthood. By contrast, boys' advantage in mathematics performance increases steadily from age 9 to 27.

- Boys are more likely than girls to pursue academic programmes and occupations that make greater use of mathematics skills.

- Over time, men are able to catch up with women in reading proficiency because reading is a transversal skill that can also be mastered outside of formal education.

Human capital is a key determinant of labour market success. In the context of increasing life expectancy and longer working lives, are education systems equipping men and women with the skills necessary to thrive in modern labour markets? Are men and women equally capable of building on the skills they acquire in school through further education, training and on-the-job learning?

\section{Girls do better in school, on average, but pursue less financially rewarding careers}

In the past, women often acquired less education than men, but this is no longer true in most OECD countries: women now generally outperform men in education, and are more likely to enrol in and complete tertiary education.

When it comes to tertiary education, however, the choice of field of study is often much more important than the degree earned, and women continue to be under-represented in STEM fields and, as a consequence, in well-paid STEM occupations.
But how do these differences in occupational choices arise? Do they reflect different preferences or a lack of the skills required to succeed in those subjects and occupations? Results from standardised, large-scale assessments can begin to answer these questions. These assessments normally evaluate proficiency in both reading (or literacy) and mathematics (or numeracy) skills. Since they are both standardised and blind-graded, they can provide more robust and comparable information on the actual proficiency of participants than other sources of data, like school marks.

\section{Differences in the skills acquired by girls and boys emerge as early as primary school}

A common finding of school-based international assessments is that boys tend to outperform girls in mathematics, while girls perform better in reading. Moreover, results show that boys tend to attain either very high or very low scores, while the scores attained by most girls are clustered in the middle of the performance scale.

Less is known, however, about how gender gaps in reading and mathematics evolve over time. Are boys able to catch up with girls in reading proficiency as they get older? Do girls eventually catch up with boys in mathematics skills? Ideally, longitudinal data, whereby the same individuals are assessed at intervals over decades, would be used to answer these questions. But in the absence of internationally comparable data of this kind, an alternative method is to combine cross-sectional data from various studies, which target populations of different ages.

The Trends in International Mathematics and Science Study (TIMSS) and the Programme in Reading and Literacy Skills (PIRLS) assess the mathematics and reading skills, respectively, of children enrolled in 
4th grade (around age 9 or 10). The Programme for International Student Assessment (PISA) assesses 15-year-old students in both reading and mathematics. The Survey of Adult Skills, a product of the Programme for the International Assessment of Adult Competencies (PIAAC), tests adults, aged 16 to 65 , in literacy and numeracy. By combining data from different assessments taken at different points in time, it is possible to follow representative samples of the same birth cohort over time and see how gender gaps in reading and mathematics proficiency evolve.

People born in 1984-85 were tested in TIMSS 1995 (at age 10), PISA 2000 (at age 15), and PIAAC 2011-12 (at age 27). Unfortunately, PIRLS was not conducted in 1995; however, data from PIRLS 2001 can be assumed to be a reasonable proxy for the literacy skills that individuals born in 1984-85 had at age 10, given the lack of major trends in gender gaps in literacy proficiency observed between PIRLS 2001 and PIRLS 2006 and between PISA 2000, 2003 and 2006. Moreover, data for this kind of analysis are only available for a limited number of countries: 10 countries in the case of literacy, and 11 countries in the case of numeracy. Data for both subjects are available in only five countries: the Czech Republic, England, the Netherlands, Norway and the United States.

\section{Boys' advantage in numeracy skills increases between the ages of 9 and 27, while the gender gap in literacy closes between the ages of 15 and 27}

In numeracy (mathematics), boys have a small advantage over girls at age 9 , which grows slightly larger by the time they are 15 years old. This gap widens considerably, however, by the time they are 27. Girls, on the other hand, have a large advantage in literacy (reading) at age 9 , which grows even wider during adolescence. However, by the age of 26-27, the gap has completely disappeared, and young men and women have almost identical levels of literacy proficiency, on average.

Figure 1 / Gender gaps in literacy and numeracy

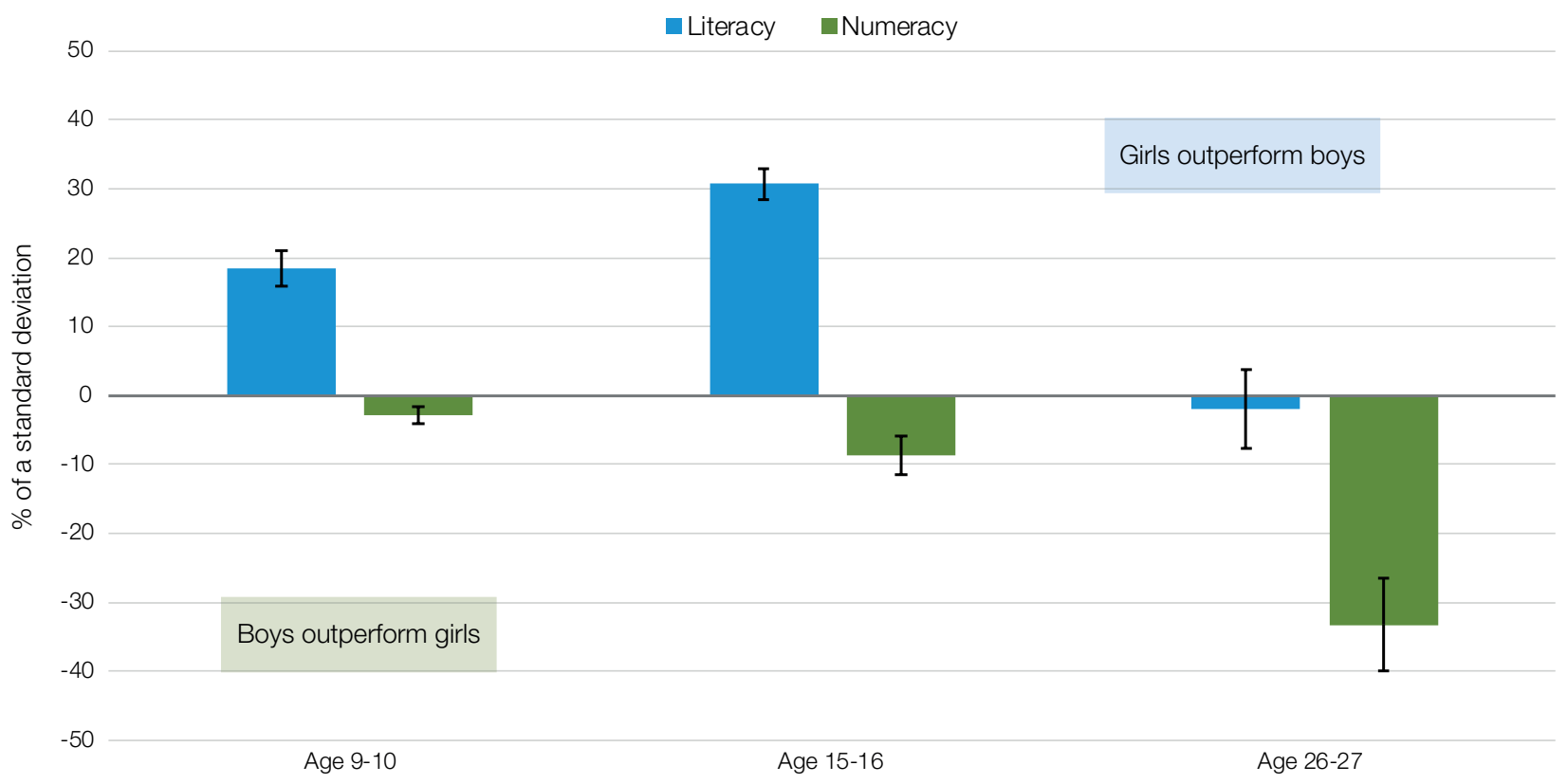

Notes: Average score of girls/women minus average scores of boys/men, expressed as a percentage of the overall standard deviation of scores in each assessment. The bands represent the standard error of the estimates. For literacy, the average is taken across the following countries: Czech Republic, France, Germany, Italy, the Netherlands, Norway, the Russian Federation, Sweden, England (UK) and the United States. For numeracy, the average is taken across the following countries: Australia, Austria, Canada, the Czech Republic, Ireland, Japan, Korea, the Netherlands, Norway, England (UK) and the United States.

Sources: TIMSS (1995), PIRLS (2001), PISA (2000) and PIAAC (2011/12). 


\section{ADULT SKILLS}

IN FOCUS

This pattern can be observed in the large majority of countries for which data are available. The gender gap in numeracy, when pupils are 9-10 years old, is not statistically significant in many countries, and is larger than $10 \%$ of a standard deviation only in Korea and the Netherlands. By the time students are 15-16 years old, gender gaps in numeracy have widened in every country except England and the Netherlands.
Amongst young adults (those aged 26-27), the gender gap in favour of men has widened in most countries (and considerably so in England, Ireland, Japan and the United States). By contrast, during this period the gender gap in numeracy has shrunk considerably only in the Czech Republic and Korea, and has remained roughly constant in Austria and the Netherlands.

\section{Figure 2 / Gender gaps in numeracy}

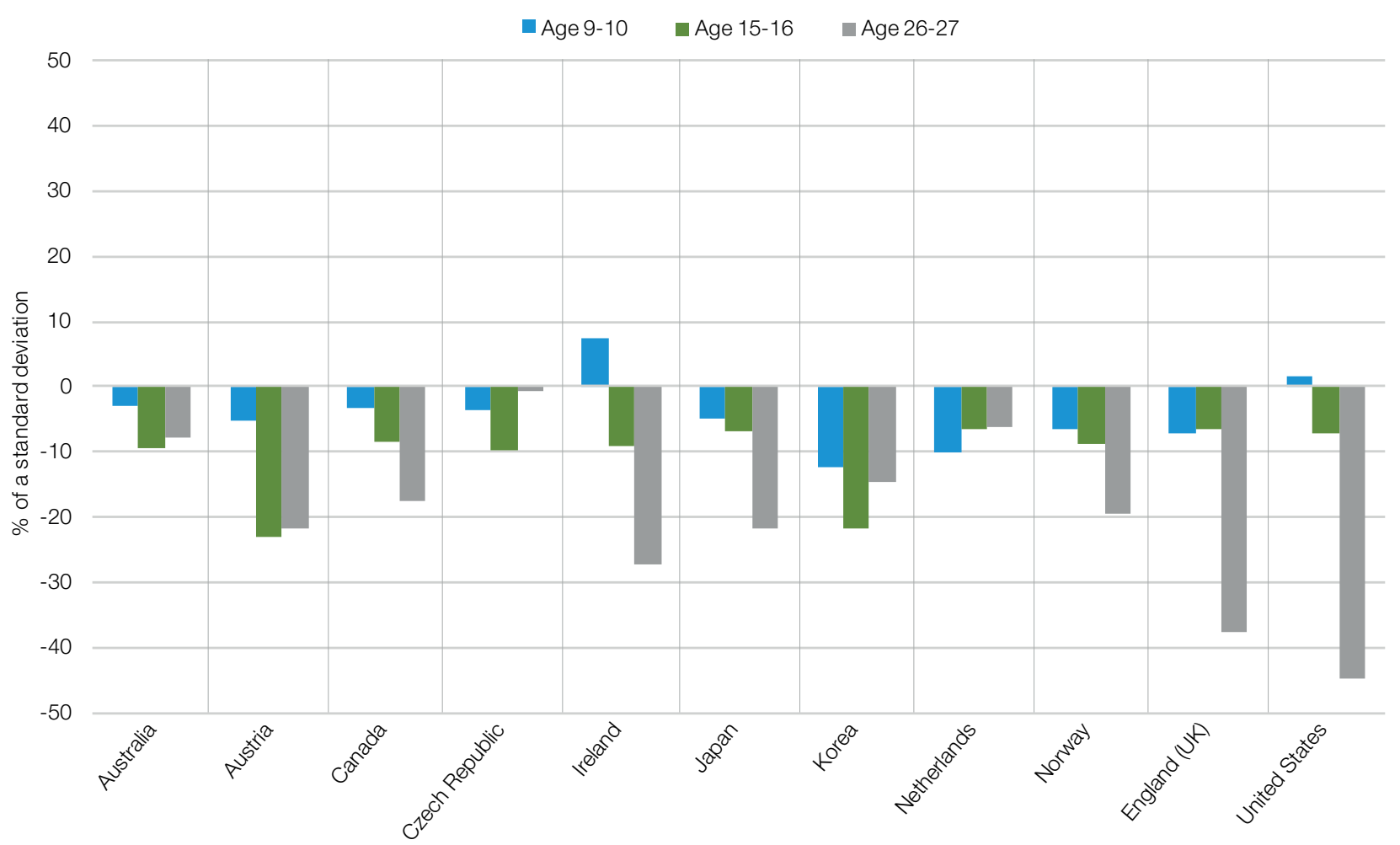

Note: Average score of girls/women minus average scores of boys/men, expressed as a percentage of the overall standard deviation of scores in each assessment.

Sources: TIMSS (1995), PIRLS (2001), PISA (2000) and PIAAC (2011/12).

Gender gaps in literacy at age 9-10 are much larger (and in favour of girls), approaching $30 \%$ of a standard deviation in England and Sweden. By age 15-16, in all countries girls have increased their advantage. However, by age 26-27, the gap has shrunk everywhere - and even inverted, in favour of young men, in England and the United States. In all countries except Italy, the gender gap in reading is no longer statistically significant.

\section{Why do gender gaps evolve over time?}

The available data from international large-scale assessments deliver a clear message: gender gaps in information-processing skills evolve differently according to the domain tested. In literacy, the advantage that girls have at early age peaks during adolescence, but then quickly disappears by early adulthood; in numeracy, the advantage of boys and men increases steadily in an almost linear way.

The data confirm the impression that girls do well at school (much better than boys in reading, and almost as well in mathematics). The roots of the gender 


\section{Figure 3 / Gender gaps in literacy}

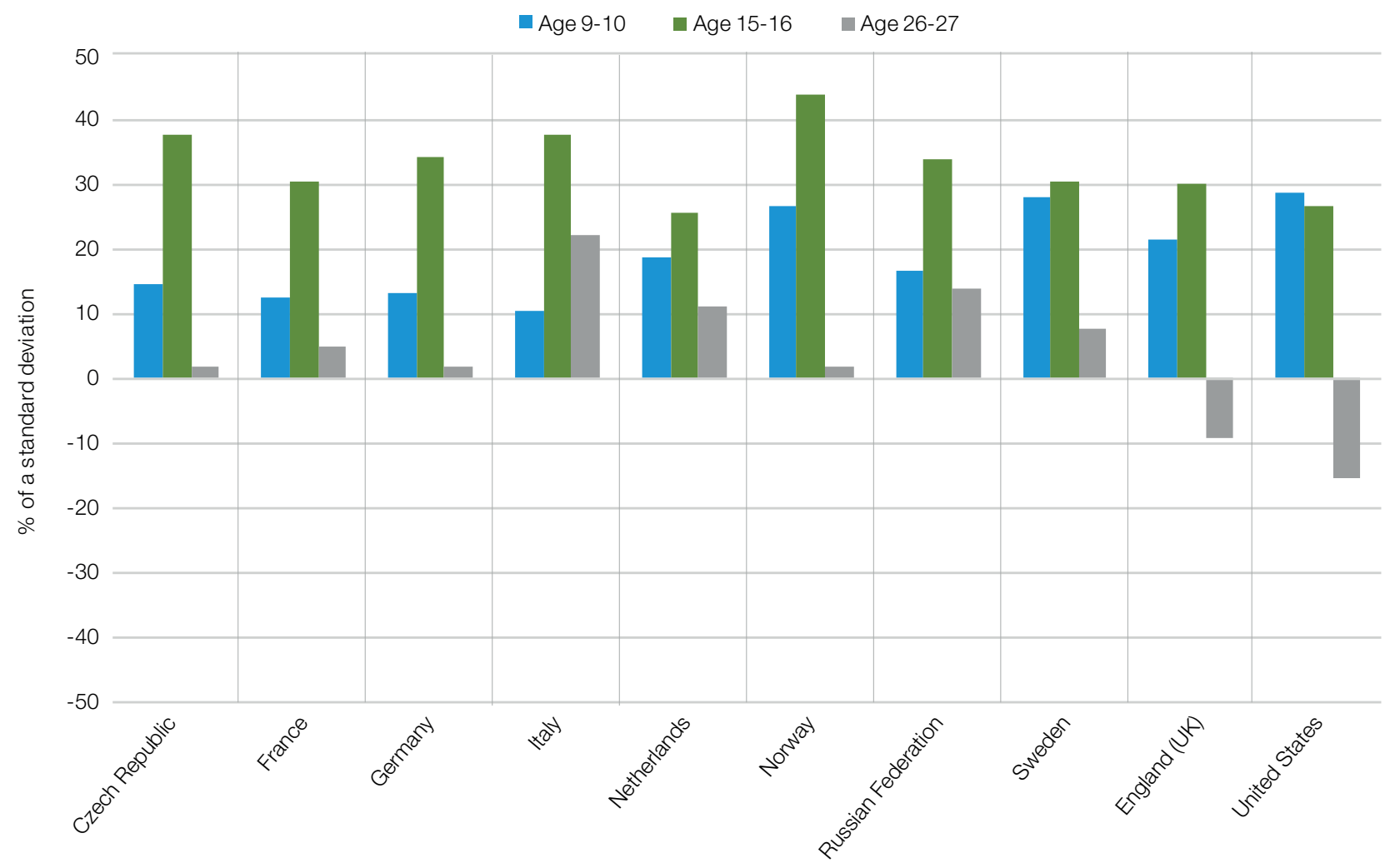

Note: Average score of girls/women minus average scores of boys/men, expressed as a percentage of the overall standard deviation of scores in each assessment.

Sources: TIMSS (1995), PIRLS (2001), PISA (2000) and PIAAC (2011/12).

gaps in labour market outcomes are then likely to lie in women's choices of field of study and career. Maybe men disproportionately specialise in fields of study and/or occupations that make more intensive use of numeracy skills because they are the only domains where they have a slight advantage over girls. This could explain the widening of the gender gap in mathematics over time. The narrowing of the gender gap in literacy is more puzzling, but it might be because literacy is a more transversal skill that everybody needs to master in order to succeed in education and in the labour market, irrespective of the chosen occupation or field of study.

But other explanations are possible, and further research is needed. Although TIMSS, PIRLS, PISA and PIAAC share many similarities, there are a number of survey-specific characteristics that may have a bearing on the observed magnitude of gender gaps. In particular, the four studies differ in terms of administration procedures, test length, mode of delivery, assessment content, response formats, response rates and treatment of missing answers or non-reached items in the scaling model used to estimate performance. TIMSS, PIRLS and PISA are conducted in schools in a group setting under the supervision of a test monitor, while the Survey of Adult Skills is conducted in a one-to-one setting in people's homes under the presence of a trained interviewer. TIMSS, PIRLS and PISA are also timed tests, while the Survey of Adult Skills does not have any formal time limit. To the extent that these characteristics affect the performance of girls/women and boys/men differently, they may partly explain the observed pattern in the evolution of gender gaps over time. 


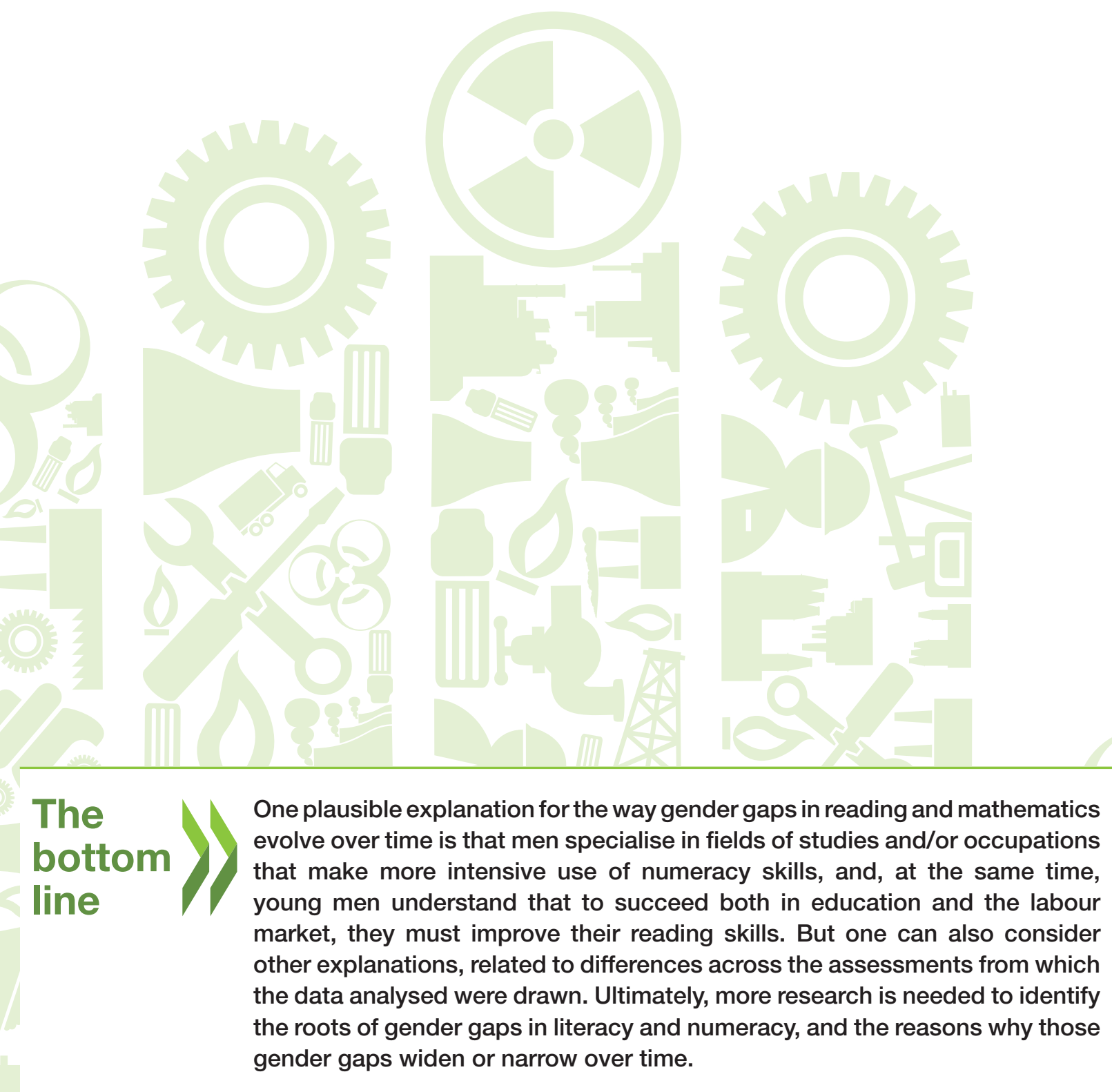

$>$ CONTACT:

$>$ FOR MORE

INFORMATION:

> VISIT:
Marco Paccagnella (Marco.Paccagnella@oecd.org) (edu.piaac@oecd.org)

Borgonovi, F., Á. Choi and M. Paccagnella (2018), «The evolution of gender gaps in numeracy and literacy between childhood and adulthood», OECD Education Working Papers, No. 184, OECD Publishing, Paris, https://doi. org/10.1787/0ff7ae72-en.

www.oecd.org/skills/piaac

Education Indicators in Focus - PISA in Focus - Teaching in Focus

The Survey of Adult Skills is a product of the OECD Programme for the International Assessment of Adult Competencies (PIAAC).

This paper is published under the responsibility of the Secretary-General of the OECD. The opinions expressed and the arguments employed herein do not necessarily reflect the official views of OECD member countries.

This document, as well as any data and any map included herein, are without prejudice to the status of or sovereignty over any territory, to the delimitation of international frontiers and boundaries and to the name of any territory, city or area.

You can copy, download or print OECD content for your own use, and you can include excerpts from OECD publications, databases and multimedia products in your own documents, presentations, blogs, websites and teaching materials, provided that suitable acknowledgment of OECD as source and copyright owner is given. All requests for commercial use and translation rights should be submitted to rights@oecd.org.

The statistical data for Israel are supplied by and under the responsibility of the relevant Israeli authorities. The use of such data by the OECD is without prejudice to the status of the Golan Heights, East Jerusalem and Israeli settlements in the West Bank under the terms of international law. 